\title{
0374 THE FARE: A NEW WAY TO EXPRESS FALLS RISK AMONG OLDER PERSONS INCLUDING PHYSICAL ACTIVITY AS A MEASURE OF EXPOSURE
}

G Jan Wijlhuizen*, A M J Chorus, M Hopman-Rock Correspondence: TNO Quality of Life, Wassenaarseweg 56, 2333 AL Leiden, The Netherlands

10.1136/ip.2010.029215.374

Objectives Common expressions of falls risk do not include exposure to hazards. We compared two expressions: the commonly used population incidence (fallers per 1000 personyears) and the FARE (FAlls Risk by Exposure): the number of fallers per 1000 physically active person-days.

Methods Prospective follow-up study among community dwelling older persons $(\mathrm{N}=771)$ aged between 71 and 96 years in the Netherlands, 2005. Baseline data on age, gender, disabilities (vision, mobility) and number of days per week with minimally 30 min of physical activity were collected. Falls were registered monthly. Falls risk was expressed as the number of falls per 1000 person-years and as the FARE. A balance control difficulty score was based on the sumscore of 11 disability items.

Results Increased difficulty controlling balance was linearly associated with reduced exposure to risky situations (Spearman correlation coefficient $=-0.56$ ) and to an increased falls risk per 1000 person-years. In contrast, the FARE score increased exponentially, which is more indicative of the real risk people face, taking into account their activity restriction. Conclusions The FARE is recommended for use in public health policy and research on falls prevention because it takes into account reduced physical activity of older persons who experience increased difficulty controlling their balance. 